\title{
Introducing the Questionnaire of Commitment to Exercise
}

\author{
Ahmad Derakhshanpoor ${ }^{1}$, Mohammad Vaez Mousavi ${ }^{2}$ \& Hmaid Reza Taheri ${ }^{3}$ \\ ${ }^{1} \mathrm{PhD}$ Candidate, Sport Psychology, Imam Reza International University, Mashhad, Iran \\ ${ }^{2}$ Professor, Imam Hossein University, Tehran, Iran \\ ${ }^{3}$ Professor, Ferdowsi University of Mashhad, Mashhad, Iran \\ Correspondence: Ahmad Derakhshanpoor, PhD Candidate, Sport Psychology, Imam Reza International \\ University, Mashhad, Iran. E-mail: ahmad_derakhshanpor@yahoo.com
}

Received: September 13, 2016 Accepted: October 26, 2016 Online Published: November 30, 2016

doi:10.5539/gjhs.v9n6p151 URL: http://dx.doi.org/10.5539/gjhs.v9n6p151

\begin{abstract}
The present study aimed to make and establish psychometric features of an exercise commitment questionnaire. The primary 35 questions were administered to 210 staffs working in Isfahan Steel Company, 120 males and 90 females. Subjects had 10 years of work experience in the company and were randomly selected using stratified sampling method. Principle component analysis and Varimax rotation were used to measure its construct validity. Finally, 25 questions were extracted with more than 0.5 loading factor indicating the validity of the instrument. Accordingly, a four-factor construct was made, being capable of explaining 58.4 percent of total variance by the use of principle component method. Results of the confirmatory factor analysis yielded features indicating positive fitness of the confirmatory analytic model of the commitment to exercise questionnaire. Also by using internal consistency reliability was calculated with Cronbach's alpha and the coefficient was 0.873 showing strong reliability. Overall, based on the satisfactory reliability and validity, this study shows that commitment to exercise questionnaire serves as a suitable measuring tool for the future research.
\end{abstract}

Keywords: commitment, exercise, validity, factor analysis, reliability

\section{Introduction}

Exercise has advantageous effects on different physical and mental aspects, and would also delay aging process (Gillespie et al., 2009).Considering many physical and mental benefits like cardiovascular function improvement, reinforcing muscles and body balance (Buchner, Beresford, Larson, LaCroix, \& Wagner, 1992), boosting self-esteem and total life enhancement quality, small number of participants in exercising as the general health interferer is the major limitation to physical activities(Tiedemann, Sherrington, \& Lord, 2011). Therefore, participation of people from different social backgrounds in physical and sport-like activities has been emphasized as a matter of interest for sports science experts. Commitment is an important concept which nowadays is been viewed for studying. (Wilson et al., 2004).

By manifesting positive thinking and also planning hopeful psychology and commitment theory, frequent educational, investigational, and remedial interferers has been done to study its effects on the other aspects of the positive features(Snyder, Cheavens, \& Michael, 2005). Commitment is a sense of dependency and fixation to a particular behavior which shows the perseverance and persistence of an individual to keep on doing his or her participation in that behavior. The sport commitment as a psychological structure exhibits an individual's desire to take part in ongoing sport activities and reflects some individual motivational forces for participation and insistence on continuing this behavior (Sousa, Torregrosa, Viladrich, Villamarín, \& Cruz, 2007).

The concept of the research of Scanlan et al., (1993) by using the theoretical foundations of commitment in systematic and social behavior and the commitment usage in sports areas, led to the suggestion of sport commitment model.

Sport Commitment model is designed based on theoretical framework of Commitment and explanation of how athletes continue their exercises (Scanlan, Russell, Beals, \& Scanlan, 2003; Sousa et al., 2007). In this model, five major factors have been established as the determining components which have been derived from Social Exchange Theory, Kelley's model of interpersonal relationship and Rusbult's investment model (Scanlan, Simons, Carpenter, Schmidt, \& Keeler, 1993; Sousa et al., 2007). These components are: sport enjoyment, personal 
investment, social constraints (peer pressure), involvement alternatives and participation opportunities (Andrew, 2004; Scanlan et al., 1993; Sousa et al., 2007). Scanlan, after nearly 25 years, amended his Sport Commitment Questionnaire. This questionnaire administered to two separate heterogeneous samples of athletic teenagers.

The new sport commitment model was presented in seven sources which five of them was related to the major model including sport enjoyment, valuable opportunities (previously was known as participation opportunities), other priorities (previously was known as involvement alternatives), personal investments, peer pressure, and the two left sources related to the new model including social support and desire to excel (Scanlan, Chow, Sousa, Scanlan, \& Knifsend, 2016).

Weiss, Kimmel, and Smith (2001) have presented a model for commitment to exercise in which sport enjoyment is introduced as a mediator and a key factor. According to the exercise commitment mediator model, any factor which leads to an increase in individuals' pleasure and interest in physical activities and sport can motivate the individual to continue the activity (Wilson et al., 2004).

Breakman (1987) suggested that the identity of commitment is a combination of both functional and obligatory components. In other words, individuals are stuck in their attempts because they want so and are also obliged to do so. In particular, individuals can be actively committed to both functional and obligatory components in any second, while these levels possibly can vary or fluctuate (Brickman, Sorrentino, \& Wortman, 1987). Both enthusiastic and imposed commitment manifests functional and obligatory components. In sport commitment model, the indirect support of distinction between enthusiastic and imposed commitment can be clearly observed in controlled and independent motivations which are correlated with self-determination theory. Self-determination can be observed when individuals are up to performing a behavior with their full control over it. In this manner, the individual takes part in behaviors in which he or she finds them meeting his or her natural beliefs and values. Research has shown that organized self-determining behaviors (in areas like education, career and sport) provide mental health in everybody's life, whereas being convinced or inevitable are the outcomes of controlled motivations (Edward L Deci \& Ryan, 2008).

Pasman and Thompson obligatory exercise model is designed in order to investigate exercise obligation and would aid psychological experts to assess individual's problem in excessive and obsessive compulsion to exercise In this model, three factors have been assigned as major and determining components which areas: frequency and intensity of exercise, negative emotionality and preoccupation with exercise (Ackard, Brehm, \& Steffen, 2002). Considering different genders, there were different reasons for obligatory exercise. For women the incentive was to maintain the appearance and for men, physical readiness and health were the motivational ideas (Furnham, Badmin, \& Sneade, 2002).

One way for a better comprehensive understanding of commitment to exercise concept is to investigate elements and components which have been assigned for commitment to exercise. A coherent scale with the ability to evaluate the multi-dimensional concept of commitment to exercise has not yet been designed. The related measurements in this area including Scanlan exercise commitment $(1993,2016)$, more likely assess athletes' commitment to exercise. Pasman and Thompson's 20 -item questionnaire (1988) was also designed to measure the obligatory exercise and the problem of obsessive exercising (Brehm \& Steffen, 1998). Considering the fact that low participation rate in exercise as general health interference is the major limitation in physical activities (Tiedemann et al., 2011), constructing a test with a capability of multiple components evaluation which is also able to assess commitment to exercise, has its own essential importance. According to the theoretical principles and research findings, the main purpose of this study was to provide a highly reliable and valid instrument within the area of commitment to exercise.

\section{Research Methodology}

\subsection{Research Method}

The current study in terms of functional aim and manner of data collection is a descriptive correlational study.

\subsection{Participants}

The population of the current study was the total 635 employees with more than 10 years of work experience working in administrative sections of Isfahan Steel Company including both men and women. Then, 235subjects were selected using stratified random sampling and in accordance with the Morgan table (Krejcie\& Morgan, 1970), However, 210 participants ultimately returned their completed questionnaires. Given that the required sample in factor analysis study has been suggested 5 to 10 subjects for each question and since the preliminary scale consisted of 35 questions, therefore the 210 -subject-sample seemed adequate. Finally, 210 subjects ( 90 women and 120 men) with the mean age of 41, standard deviation of 3 and the domain of 33 to 49 years (with 95 percent 
confidence interval) were considered as the study samples.

\subsection{Instruments}

Constructing and validating the commitment to exercise questionnaire was designed by reviewing the theoretical foundations and considering the features of promising individuals to exercise. The theoretical foundations were emphasizing the usage of components in questionnaire which include fascination to exercise, frequency and intensity of exercise, reinforcer and barriers. These factors are based on theory of health belief model (Becker, 1974), transtheoretical model (Richard, Christina, Deborah, Rubio, \& Kennon, 1997) theory of planned behavior (TPB) (Ajzen, 1991) and self-determination theory (E. L Deci \& Ryan, 1991). Relying on theoretical foundations, the primary questionnaire was designed. This tool was pretested and given to some subjects and sports psychology experts to judge the theoretical foundations and composing style, so that face and content validity could be examined before the major utilization. For investigating the content validity of questionnaire, content validity ratio and content validity index methods were applied. Then, according to Lawshe's content validity ratio the content validity ratio and content validity index were computed 0.88 and 0.87 respectively which shows that the content validity of Iranian exercise commitment questionnaire is sufficient. Also their comments on rewriting, dropping, adding, and amending the items were applied.

This questionnaire was designed in 5-item Likert Scale from 1 (never) to 5 (always) and was administered to the research sample. The four components of this questionnaire are as follows:

1) Fascination to exercise: Fascination was first innovated and described by Csikszentmihalyi (2000). According to his definition, the fascination experience possibly can appear in any condition in which executing the activity is essential. Researchers have found evidences indicating that fascination occurs while different activities like exercising takes place (Engeser \& Rheinberg, 2008). Items 3, 6, 11, 14, 16, 17, 18, 23, 24, and 25 measure fascination to exercise.

2) Frequency and intensity of exercise: When some people begin a particular activity, their next trouble is maintaining and sticking to the plan. This problem can be explained with frequency and intensity of exercise. Research has shown that sticking to exercise is negatively correlated with intensity of the exercise. When the exercise time is long or intense, the joy and happiness, caused by exercising, will gradually fade away (Lamb, Bartlett, Ashley, \& Bird, 2002). Items 1, 2, 5 and 9 measure the frequency and intensity of exercising.

3) Barriers: Despite the personal and social advantages of exercising, many will avoid exercising. Sallis et al., (1990) identified 17 potential factors preventing individuals from exercising. Some of these factors can be pointed out as: shortage of time and money, being far away from the living location, injuries, bad weather, lack of energy and motivation (Vaez Mousavi \& Mosayyebi, 2011). Items 10, 15, 20 and 21 measure the barriers.

4) Reinforcing Factors: Many reasons can motivate people; therefore one proper way to motive individuals is to emphasize different benefits of exercising. When people intend to start a particular activity like exercising, they can be motivated by internal and external incentives (Marcus et al., 2000). Items 4, 7, 8, 12, 13, 19 and 22 measure the Reinforcing factors.

In this study, Scanlan's commitment to exercise questionnaire (1993) has been used for investigating convergent validity. This questionnaire is a 26 -item Likert questionnaire with five-level grading style from strongly agrees to strongly disagree. The commitment to exercise questionnaire is constructed with five subscales which its titles are: sport enjoyment, involvement alternatives, personal investments, peer pressure, and participation opportunities. Every individual's commitment to exercise point can be calculated by adding subscale points. The reliability and validity of Scanlan'scommitment to exercise questionnaire was measured and confirmed in Mir Hosseini et al., research (2011), and also Cronbach's Alpha coefficient was reported 0.70 .

\subsection{Procedure}

After clarifying the goals of the study, establishing needed coordination with steel company authorities, the instructions were given and the necessity and importance of correct answering were explained. Then, the questionnaires were distributed among the staffs in each administrative sections of company and staffs were asked to answer them. Although time limitation for answering the questionnaire was not specified, the needed time for responding did not exceed 25 minutes. To ensure that subjects' answering process is taking place accordingly and correctly, colleagues and researchers were supervising at the administration location during the whole process. Additionally, there was no obligation executed for participation in research process.

\subsection{Statistical Methods}

The statistical methods used in this study were descriptive and inferential. For calculating central tendencies and 
variability, descriptive method was used; also inferential methods like exploratory factor analysis were used as a method to identify constructing factors of commitment to exercise. Then for acquiring more precise fitness of objective matrix loadings, confirmatory factor analysis was conducted.

\section{Results}

After investigating the content validity of the questionnaire with the help of the experts in this field, validity of the questionnaire was investigated (shown in Table 1) by using major component method of factor analysis. After conducting the exploratory factor analysis for five times, 10 items were omitted because of improper factor loading. Eventually, the final version of commitment to exercise questionnaire with 25 items was identified and named according to below mentioned explanation of the results in four dimensions.

Table 1. Test results of Kaiser-Meyer-Olkin (KMO) and Bartlett, stage five as a license for implementing factor analysis

\begin{tabular}{lcc}
\hline \multicolumn{2}{c}{ Sample adequacy ratio } & 0.769 \\
\hline The approximate ratio in chi-square & 1214.186 \\
test & $d f$ & 300 \\
Test results & Level of Significance & 0.0001 \\
\hline
\end{tabular}

According to Table 1, the factor analysis sample was a decent sample. If sample adequacy ratio amount is more or equal to 0.5 , the concordance between data is appropriate for factor analysis, and the 0.769 amount is exhibiting desirability and profitability of the sample volume for factor analysis. Bartlett's test ofsphericity2, measures the theory in which matrix evaluates the observed concordance in populations with discordant variables. The amounts which are smaller than 0.05 shows the level of significance in which the factor analysis is properforits data. In other words, besides sample adequacy ratio, conducting factor analysis based on the studied subjects would also be justifiable.

Table 2. Special values and variance percentage of derived variables

\begin{tabular}{llll}
\hline Components & The special amount & $\begin{array}{l}\text { Percentage of explained } \\
\text { variance }\end{array}$ & $\begin{array}{l}\text { The cumulative percentage } \\
\text { of explained variance }\end{array}$ \\
\hline 1 & 3.456 & 22.325 & 22.325 \\
2 & 1.487 & 13.519 & 35.845 \\
3 & 1.365 & 13.409 & 48.354 \\
4 & 1.117 & 10.155 & 58.409 \\
\hline
\end{tabular}

According to Table 2, four factors with special value which is more than one could be derived before rotation which in total, explains $58.409 \%$ of a questionnaire`s variance. Such data showed that the major amount of matrix variance can be explained by four components and the other factors have little impact on explaining the variance.

In the next level, the primary statistical index was implemented by major component method using Varimax rotation; items were rotated so that they can manifest more factor loadings on elements. After conducting the exploratory factor analysis for five times, 10 items were omitted because of improper factor loadings, and at the end, the final version of for five times commitment to for five times questionnaire with 25 items was identified and named in four dimensions according to the below mentioned explanation of the results. 
Table 3. Results of the factor analysis of the commitment to exercise questionnaire by the use of the main elements and Varimax rotation

\begin{tabular}{|c|c|}
\hline Fascination to exercise items & Amount \\
\hline 3- When I do not exercise, I feel regret and guilty. & 0.665 \\
\hline 6- I feel so energetic and happy after one set of exercising. & 0.661 \\
\hline 11- If I quit exercising, it will have some negative effects on my health. & 0.610 \\
\hline 14- I believe whenever I planned for exercising, I succeeded in doing that. & 0.619 \\
\hline 16- I exercise because of my inner desire, not anyone else's motivations. & 0.689 \\
\hline 17- I like exercising outdoor. & 0.600 \\
\hline 18- I feel proud of myself because I have regular exercising compared to my peers. & 0.569 \\
\hline 23- I spend money on my exercise equipment and cloth. & 0.643 \\
\hline 24- I daydream about my fitness which is the fruit of my exercise. & 0.604 \\
\hline 25- I ponder about my exercise schedule. & 0.666 \\
\hline \multicolumn{2}{|l|}{ Reinforcer Items } \\
\hline 4- My best friend likes exercising. & 0.674 \\
\hline 7- Whenever I have been recommended to exercise by my doctor, friend and etc. I tried to do so. & 0.720 \\
\hline 8- I encourage my friends to exercise. & 0.659 \\
\hline 12- I have important people (spouse, child and friends) in my life who believe I should exercise. & 0.664 \\
\hline $\begin{array}{l}\text { 13- Important people in my life (spouse, child and friends) manage their schedule in a way that matches my } \\
\text { exercise schedule. }\end{array}$ & 0.634 \\
\hline 19- Exercising is an opportunity to hang out with my friends. & 0.670 \\
\hline $22-$ I try to find a friend or a companion in sports venues. & 0.597 \\
\hline \multicolumn{2}{|l|}{ Frequency and Intensity Items } \\
\hline 1- I exercise every day. & 0.750 \\
\hline 2- I exercise at least three days a week. & 0.642 \\
\hline 5- If I miss one day of my exercise schedule, I try to make it up on other day. & 0.723 \\
\hline 9- I have specified a particular time for exercising. & 0.650 \\
\hline \multicolumn{2}{|l|}{ Disturber Factor Items } \\
\hline 10- Sometimes I miss my exercise due to the lack of energy or time. & 0.670 \\
\hline $\begin{array}{l}\text { 15- I quit exercising because of different reasons (lack of time, having a career, family issues, bad weather and } \\
\text { insecurities). }\end{array}$ & 0.650 \\
\hline 20- I miss my exercise sessions due to the daily life issues. & 0.690 \\
\hline 21- I believe whenever I miss some of my exercise sessions, I experience some troubles starting a new schedule. & 0.700 \\
\hline
\end{tabular}

Table 3 has shown the relationship between items and factors. The matrix result of the rotated factors showed that this group of items, measures the commitment to exercise in four dimensions which are: fascination to exercise, reinforcer factors, frequency and intensity and Barriers. These results confirmed the validity of the construct as a four-dimension tool for evaluating and measuring the individuals' commitment to exercise.

\subsection{Confirmatory Factor Analysis}

The output of the LisrelSoftwareis equal to 1.6 for the chi-square of the $d f\left(\chi^{2} / d f\right)$ which is mentioned inTable 4 . The fact is that this amount is less than 2 , and the presence of this ratio and the other results are mentioned in Table 5 , that all of them are the output of LisrelSoftware, are vividly stating and emphasizing the decent fitness of the model. 
Table 4. goodness of fit index

\begin{tabular}{llll}
\hline The Index Name & $\begin{array}{l}\text { The Standard Index } \\
\text { Amount }\end{array}$ & $\begin{array}{l}\text { The Index Amount in } \\
\text { Particular Model }\end{array}$ & Conclusion \\
\hline Chi square & - & 427.99 & Decent model fitness \\
P value & Bigger than 0.05 & 0.504 & Decent model fitness \\
GFI (Goodness of Fit Index) & Bigger than 0.9 & 0.93 & Decent model fitness \\
AGFI (Adjusted Goodness of Fit Index) & Bigger than 0.9 & 0.90 & Decent model fitness \\
NFI (Normed Fit Index) & Bigger than 0.9 & 0.95 & Decent model fitness \\
CFI (Comparative Fit Index) & Bigger than 0.9 & 0.95 & Decent model fitness \\
$\begin{array}{l}\text { RMSEA (Root Mean Square Error of } \\
\text { Approximation) }\end{array}$ & Smaller than 0.1 & 0.063 & Decent model fitness \\
\hline
\end{tabular}

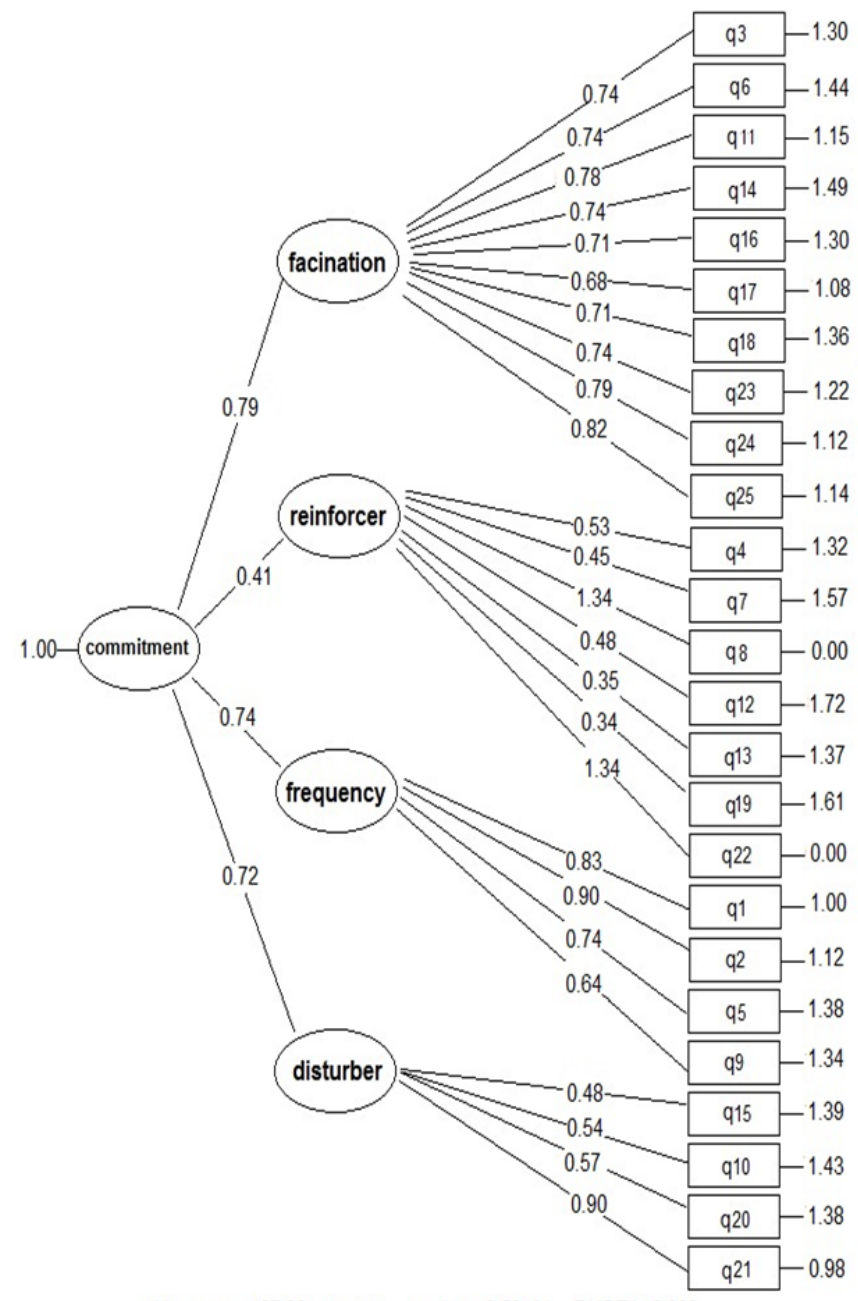

chi_square $=427.99 \mathrm{df}=271 \mathrm{p}$-value $=0.50431$ RMSEA $=0.063$

Figure 1. Second order factor analysis questionnaire mode

For investigating the significance level of factor analysis coefficients, the significance level test was conducted according to t-value index, and Lisrel software outputs show significance level of each coefficient. Regarding the fact that all coefficients are higher than 1.96, therefore the mentioned model and its coefficients are bearing decent level of significance. 


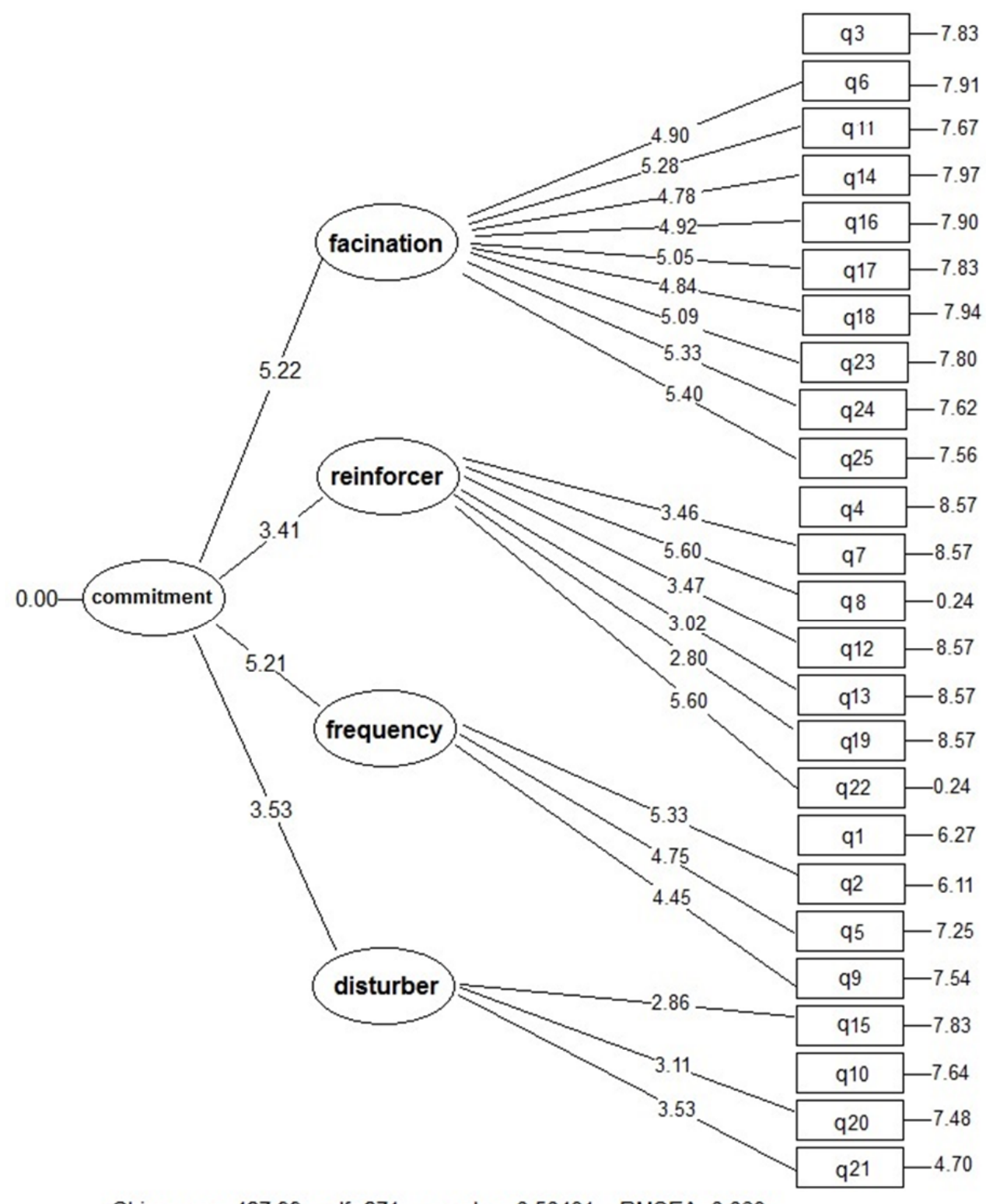

Chi-square $=427.99 \mathrm{df}=271 \quad \mathrm{p}$-value $=0.50431 \quad \mathrm{RMSEA}=0.063$

Figure 2. Significant coefficient model of second order factor analysis

For investigating the reliability of the questionnaire by using the SPSS Software, the confidence coefficient amount was calculated, using the internal consistency method (Cronbach's alpha coefficient) which is explained in Table 5. These numbers showed that the questionnaire is trustable and in other words, is sufficiently reliable.

Table 5. Questionnaire Confidence Coefficient

\begin{tabular}{|c|c|c|c|}
\hline $\begin{array}{l}\text { Total } \\
\text { amount }\end{array}$ & Cronbach's alphacoefficient & Total number of items & $\begin{array}{l}\text { Cronbach's alpha coefficient of questionnaire } \\
\text { dimensions }\end{array}$ \\
\hline & & & Frequency and Intensity: 0.721 \\
\hline \multirow[t]{3}{*}{0.873} & & 25 & Fascination to exercise: 0.871 \\
\hline & & & Reinforcer factors: 0.755 \\
\hline & & & Barriers: 0.717 \\
\hline
\end{tabular}


According to the Table 5, the total Cronbach's alpha coefficient amount was 0.873 which states high internal consistency of this scale. Also among the components, fascination to exercise has the highest reliability coefficient which stresses the importance of internal motivation and the pleasure beneath exercising.

\section{Discussion and Conclusion}

The current study was conducted for the sake of constructing and determining the psychological features of Iranian commitment to exercise questionnaire. For constructing this questionnaire, the theoretical history of exercise commitment and the related questionnaires in this field have been analyzed. The extracted factors derived from this study have built the foundations of the initial item scale exactly according to the theory-based models such as health belief model, transtheoretical model, theory of planned behavior and self-determination theory. The similar subject related to this matter was also considered and the improper subjects were omitted; then face and content validity of the questionnaire were confirmed by the experts. In this way, content validity ratio and content validity index were calculated respectively as 0.88 and 0.87 which are sufficient amounts for reliability and validity of the Iranian commitment to exercise questionnaire. Some experts' suggestions considering item clarity were applied in the final preparation before administration. Exploratory factor analysis was utilized for investigating the construct validity. The sample adequacy amount was 0.769 with 99 percent confidence level indicating that the research data has the capability for factor analysis. In addition, after conducting exploratory factor analysis, each component shares or their special value and explanatory variance power of the test were determined; in a way that, four factors with values more than one, have explained 58.409 percent of the total variance which shows that the commitment to exercise questionnaire is a multi-dimensional construct with four factors including: fascination to exercise, reinforcer factors, frequency and intensity of exercise and barriers. For ensuring the results of the exploratory factor analysis to be correct, the confirmatory factor analysis was applied, using Lisrel software. The chi-square of the $d f$ was equal to 1.6 and the other indexes derived from outputs of Lisrel software indicated that the fitness is sufficient for the second order factor analysis of the commitment to exercise. The results of this study indicated that the commitment to exercise questionnaire can be used for measuring and evaluating the individuals' commitment to exercise. The factors derived from this study were in harmony with part of the research results of Scanlan et al. they are positively correlated in more than two factors; for instance, in Scanlan's commitment to exercise questionnaire validation, Mir Hosseini et al., (2011) showed that Cronbach's alpha coefficient in sport enjoyment is 0.86 and in peer pressure factor is 0.90 which are positively correlated with fascination to exercise and Barriers in this study(Mirhossayni, Hadavi, \& Mozaffari, 2012).

Weiss, Kimmel, and Smith (2001) have presented a model for commitment to exercise in which sport enjoyment is introduced as a mediator and a key factor. The proposed model in this study nearly supports factor combination and multi-dimensional structure of commitment to exercise and its components.

The 20-itemobligatory exercise questionnaire includes dimensions such as: negative emotionality, frequency and intensity of exercise and the preoccupation with exercise (Ackard et al., 2002). According to Pasman \& Thompson's questionnaire, Cronbach'salpha coefficient in frequency and intensity factor and preoccupation with exercise respectively was $79 \%$ and $68 \%$ (Brehm\& Steffen, 1998), which are in line with frequency and intensity components in the present study. Regarding the results of the present study, from among the components related to commitment to exercise, the highest average goes to the fascination to exercise index which indicates the importance of inner motivation for exercising physical activities and enjoying that particular activity.

The general conclusion of all findings shows that commitment to exercise includes extensive dimensions; in a way that despite progress in motivation to exercise and the individual's feeling of effectiveness and ability in doing the exercise duties according to the schedule, it also includes other dimensions like fascination to exercise (Csikszentmihalyi, 2000), frequency and intensity of exercise (Lamb et al., 2002), reinforcer factors (Marcus et al., 2000) and barriers (Vaez Mousavi \& Mosayyebi, 2011). The literature in sports sciences clearly emphasizes the role of these factors in individuals' commitment to exercise, in a way that sports science experts expressed that the difference between promising individuals to exercise and less promising ones is connected to these factors. Therefore, commitment to exercise questionnaire and its components has decent and desirable validity and reliability; and has the potentials to measure individuals' commitment to exercise. Scanlan's commitment to exercise questionnaire is particularly designed to measure athletes' commitment and the obligatory questionnaire is also constructed to measure excessive, extreme and obsessive activities. This questionnaire can measure individuals' commitment to exercise among people who exercise only for the sake of preserving health and its enjoyment, and can also be a helpful aid for psychologists and consolers for interfering the individuals' perspectives in order to make their clients more promising and stick to this vital matter. Besides, in general, these results can be translated towards a general patient population such as evaluating the commitment to cardiac 
rehabilitation in heart failure. This study was administered among the staffs in steel company who were 33 to 43 years old, so a close care must be taken for generalizing the findings. Therefore, it is suggested that this scale can be administrated to other populations except steel company staffs, so that establishments for another validation can be available.

\section{Acknowledgements}

Providing and determining the psychometric characteristics are from among the required measurement tools for a $\mathrm{PhD}$ dissertation which is done by the sponsorship of Isfahan Steel joint stock Company. It is necessary to deeply acknowledge and appreciate R \& D manager and staff of the company who kindly cooperate to conduct this survey.

\section{Competing Interests Statement}

The authors declare that there is no conflict of interests regarding the publication of this paper.

\section{References}

Ackard, D. M., Brehm, B. J., \& Steffen, J. J. (2002). Exercise and eating disorders in college-aged women: $\begin{array}{lllll}\text { Profiling excessive } & \text { exercisers. }\end{array}$ https://doi.org/10.1080/106402602753573540

Ajzen, I. (1991). The Theory of Planned Behavior Prganizational Behavior and Human Decision Processes. Milton Keynes, England: Open University Press.

Andrew, D. P. S. (2004). Effect of Congruence of Leadership Behaviors on Motivation, Commitment, and Satisfaction of College Tennis Players (PhD, Florida state University, U.S.A.).

Becker, M. H. (1974). The health belief model and personal health behavior (Vol. 2): Slack.

Brehm, B. J., \& Steffen, J. J. (1998). Relation between obligatory exercise and eating disorders. American Journal of Health Behavior.

Brickman, P., Sorrentino, R. M., \& Wortman, C. B. (1987). Commitment, conflict, and caring. Englewood Cliffs, NJ: Prentice Hall.

Buchner, D. M., Beresford, S. A., Larson, E. B., LaCroix, A. Z., \& Wagner, E. H. (1992). Effects of physical activity on health status in older adults II: Intervention studies. Annual review of public health, 13(1), 469-488. https://doi.org/10.1146/annurev.pu.13.050192.002345

Csikszentmihalyi, M. (2000). Beyond boredom and anxiety. San Francisco: Jossey-Bass.

Deci, E. L., \& Ryan, R. M. (1991). A Motivational Approach to Self: Integration in Personality. In R. Denstbier (Ed.), Perspectives on motivation (Vol. 38, pp. 237). Lincoln: University of Nebraska Press.

Deci, E. L., \& Ryan, R. M. (2008). Facilitating optimal motivation and psychological well-being across life's $\begin{array}{lllll}\text { domains. } & \text { Canadian Psychology/Psychologie } & \text { canadienne, } & 49(1), & 14 .\end{array}$ https://doi.org/10.1037/0708-5591.49.1.14

Engeser, S., \& Rheinberg, F. (2008). Flow, performance and moderators of challenge-skill balance. Motivation and Emotion, 32(3), 158-172. https://doi.org/10.1007/s11031-008-9102-4

Furnham, A., Badmin, N., \& Sneade, I. (2002). Body image dissatisfaction: Gender differences in eating attitudes, self-esteem, and reasons for exercise. The Journal of psychology, 136(6), 581-596. https://doi.org/10.1080/00223980209604820

Gillespie, L. D., Robertson, M. C., Gillespie, W. J., Lamb, S. E., Gates, S., Cumming, R. G., \& Rowe, B. H. (2009). Interventions for preventing falls in older people living in the community. Cochrane Database Syst Rev, 2(CD007146). https://doi.org/10.1002/14651858.cd007146.pub2

Krejcie, R. V., \& Morgan, D. W. (1970). Determining sample size for research activities. Educational and Psychological Measurement, 30, 607-610.

Lamb, S. E., Bartlett, H., Ashley, A., \& Bird, W. (2002). Can lay-led walking programmes increase physical activity in middle aged adults? A randomised controlled trial. Journal of epidemiology and community health, 56(4), 246-252. https://doi.org/10.1136/jech.56.4.246

Marcus, B. H., Forsyth, L. H., Stone, E. J., Dubbert, P. M., McKenzie, T. L., Dunn, A. L., \& Blair, S. N. (2000). Physical activity behavior change: issues in adoption and maintenance. Health Psychology, 19(1S), 32. https://doi.org/10.1037/0278-6133.19.Supp11.32 
Mirhossayni, M., Hadavi, F., \& Mozaffari, A. (2012). The Reliability and Validity of Exercise Commitment Model among Students Athletes. Journal of The Faculty of Physical Education And Sport Sciences, 15(4), 105-121.

Richard, M., Christina, M. F., Deborah, L. S., Rubio, N., \& Kennon, M. S. (1997). Intrinsic motivation and exercise adherence. Int J Sport Psychol, 28(4), 335-354.

Scanlan, T. K., Chow, G. M., Sousa, C., Scanlan, L. A., \& Knifsend, C. A. (2016). The development of the Sport Commitment Questionnaire-2 (English version). Psychology of Sport and Exercise, 22, 233-246. https://doi.org/10.1016/j.psychsport.2015.08.002

Scanlan, T. K., Russell, D. G., Beals, K. P., \& Scanlan, L. A. (2003). Project on elite athlete commitment (PEAK): II. A direct test and expansion of the sport commitment model with elite amateur sportsmen. Journal of Sport and Exercise Psychology, 25(3), 377-401. https://doi.org/10.1123/jsep.25.3.377

Scanlan, T. K., Simons, J. P., Carpenter, P. J., Schmidt, G. W., \& Keeler, B. (1993). The Sport Commitment Model: Measurement development for the youth-sport domain. Journal of Sport \& Exercise Psychology, 15(1). https://doi.org/10.1123/jsep.15.1.16

Snyder, C., Cheavens, J. S., \& Michael, S. T. (2005). Hope Theory: History and Elaborated Model. In J. Elliot (Ed.), Interdisciplinary Perspectives on Hope (pp. 219-223). Hauppauge, NY: Nova Science Publishers.

Sousa, C., Torregrosa, M., Viladrich, C., Villamarín, F., \& Cruz, J. (2007). The commitment of young soccer players. Psicothema, 19(2), 256-262.

Tiedemann, A., Sherrington, C., \& Lord, S. R. (2011). Predictors of exercise adherence in older people living in retirement villages. Preventive medicine, 52(6), 480-481. https://doi.org/10.1016/j.ypmed.2011.03.015

Vaez Mousavi, S., \& Mosayyebi, F. (2011). Sport psychology (3rd ed.). Tehran: Samt publication.

Wilson, P. M., Rodgers, W. M., Carpenter, P. J., Hall, C., Hardy, J., \& Fraser, S. N. (2004). The relationship between commitment and exercise behavior. Psychology of Sport and Exercise, 5(4), 405-421. https://doi.org/10.1016/S1469-0292(03)00035-9

\section{Copyrights}

Copyright for this article is retained by the author(s), with first publication rights granted to the journal.

This is an open-access article distributed under the terms and conditions of the Creative Commons Attribution license (http://creativecommons.org/licenses/by/4.0/). 